Библиографический список

1. Khrapov S.S., Pisarev A.V., Kobelev I.A., Zhumaliev A.G., Agafonnikova E.O., Losev A.G. and Khoperskov A.V. The Numerical Simulation of Shallow Water: Estimation of the Roughness Coefficient on the Flood Stage // Advances in Mechanical Engineering. Volume 2013, Article ID 787016, 11 pages.

2. Воеводин А. Ф., Никифоровская В.С., Виноградова Т.А. Математические модели для прогнозирования процесса распространения волн катастрофических паводков в системах открытых русел и водотоков // Вестник Санкт-Петербургского университета, Сер. 7, 2009, вып. 3, С. 139-144.

3. Воронин А.А., Елисеева М.В., Писарев А.В., Хоперсков А.В., Храпов С.С. Имитационные модели динамики поверхностных вод с использованием данных дистанционного зондирования: влияние рельефа местности // Прикаспийский журнал: управление и высокие технологии. 2012, № 3(19), С. 54-62.

4. Егоров В.А. Численные расчеты вязких течений в модельных руслах с поймой // Математические заметки ЯГУ, 2009, Т. 15, Вып. 2, С. 92-105.

5. Еремин М.А., Хоперсков А.В. Компьютерная модель прорыва Волжской // Вестник Волгоградского государственного университета, Серия 1: Математика. Физика, 2006, Т.10, С. 139-142.

6. Кивва С.Л., Железняк М.И. Численное моделирование двумерного открытого потока с подвижными границами: расчеты стока на водосборе и наката волн цунами на берег // Вычислительные технологии, 2001, Т.6, ч.2, С.343-350

7. Педлоски Дж. Геофизическая гидродинамика в 2-х т. М.: Мир, 1984, 806 с.

8. Писарев А.В., Храпов С.С., Агафонникова Е.О., Хоперсков А.В. Численная модель динамики поверхностных вод в русле Волги: оценка коэффициента шероховатости // Вестник Удмуртского университета. Математика. Механика. Компьютерные науки, 2013, N 1, С. 114-130.

9. Х Хоперсков А.В., Храпов С.С., Писарев А.В., Воронин А.А., Елисеева М.В., Кобелев И.А. Задача управления гидрологическим режимом в эколого-экономической системе «Волжская ГЭС - ВолгоАхтубинская пойма». Ч.1. Моделирование динамики поверхностных вод в период весеннего паводка // Проблемы управления, 2012, № 5, С. 18-25.

10. Храпов С.С., Писарев А.В., Воронин А.А., Дьяконова Т.А., Циркова Е.А. Особенности динамики затопления Волго-Ахтубинской поймы в зависимости от режимов испарения и инфильтрации // Вестник Волгоградского государственного университета, Серия 1: Математика. Физика, 2012, Т.16. 1, С. 43 47.

11. Храпов С.С., Хоперсков А.В., Еремин М.А. Моделирование динамики поверхностных вод: Монография. - Волгоград: Издательство Волгоградского государственного университета, 2010, 132 с.

12. Храпов С.С., Хоперсков А.В., Кузьмин Н.М., Писарев А.В., Кобелев И.А. Численная схема для моделирования динамики поверхностных вод на основе комбинированного SPH-TVD-подхода // Вычислительные методы и программирование. 2011, Т. 12, №1, С. 282-297.

13. Храпов С.С., Хоперсков А.В, Писарев А.В., Кобелев И.А. Геоинформационная система для прогноза сезонных затоплений // ИнтерКарто-ИнтерГИС 18 : материалы Международной конференции, Россия, Смоленск, 26-28 июня 2012. - 2012, С. 386-394.

14. Чикин А.Л. Построение и численное исследование 3D модели гидродинамики Азовского моря // Труды Международной конференции, посвященной 80-летию академика Н.Н. Яненко «Современные проблемы прикладной математики и механики: теория, эксперимент и практика». Новосибирск, Академгородок, 24 - 29 июня 2001 года. «Вычислительные технологии», т.6, спецвыпуск, 2001, С.686-692.

15. Шокин Ю.И., Чубаров Л.Б., Марчук Ан.Г., Симонов К.В. Вычислительный эксперимент в проблеме цунами. Новосибирск: Наука, 1989. 168 с.

ГЕОИНФОРМАЦИОННОЕ ОБЕСПЕЧЕНИЕ ПРИ ИССЛЕДОВАНИЙ ПАРАМЕТРОВ ЭКОЛОГИЧЕСКОЙ БЕЗОПАСНОСТИ УРБАНИЗИРОВАННЫХ ТЕРРИТОРИЙ ЦЧР

\author{
С.А. Епринщев, С.А. Куролап, С.В. Шекоян \\ Воронежский государственный университет \\ 2. Воронеж, Россия E-mail:esa81@ mail.ru
}

\title{
GIS, ENSURING ENVIRONMENTAL SAFETY STUDY PARAMETERS URBANIZED AREAS OF THE CENTRAL BLACK EARTH REGION
}

\author{
S.A. Eprintsev, S.A. Kurolap, S.V. Shekoyan \\ Voronezh State University \\ Voronezh, Russia E-mail:esa81@mail.ru
}


Abstract. A model of geo-information for geo-environmental studies, including the formation and maintenance of the GIS database ( for periodic ecological and geochemical studies ); database processing ( statistical data processing, holding current calculations ), creating kartoosnovy GIS (creating "layers" of a vector map ); geocoding data ( data transformation ecogeochemical research kartoosnovy vector coordinate system ), GIS mapping ( thematic maps ), data analysis , design (development of priority actions to optimize the urban environment ).

Эффективность исследования параметров экологической безопасности напрямую связана с оперативностью обработки и анализа информации. При комплексном подходе, характерном для экологии, обычно приходится опираться на обобщающие характеристики окружающей среды, вследствие чего, объемы даже минимально достаточной исходной информации, несомненно, должны быть большими. В противном случае обоснованность действий и решений вряд ли может быть достигнута. Кроме того, полученные данные должны быть легко доступны и систематизированы. На этапе обработки и анализа собранных данных существенное, но отнюдь не первое, место занимает техническая оснащенность исследователя, включающая подходящие для решения поставленной задачи аппаратные средства и программное обеспечение. В качестве последнего во всем мире все чаще применяется современная мощная технология географических информационных систем [4].

ГИС имеет определенные характеристики, которые с полным правом позволяют считать эту технологию основной для целей обработки и управления информацией. Средства ГИС намного превосходят возможности обычных картографических систем, хотя естественно, включают все основные функции получения высококачественных карт и планов [4]. В самой концепции ГИС заложены всесторонние возможности сбора, интеграции и анализа любых распределенных в пространстве или привязанных к конкретному месту данных [4].

В качестве основных программных продуктов ГИС для проведения исследований параметроов экологической безопасности урбанизированных территорий ЦЧР использованы программы ArcGIS и MapInfo, которые наиболее удобны для реализации поставленной цели [Епринцев и др. 2013]. При помощи данных программ созданы электронные картоосновы ГИС урбанизированных территорий ЦЧР, в структуру которых входят как правило следующие векторные слои: жилая застройка; промышленная застройка; зелёные насаждения; улицы; крупные автодороги; железные дороги; рельеф; кладбища; сады; объекты гидрологии; границы районов [Куролап и др., 2010].

Слой «Жилая застройка» (рис. 1) создан при помощи «полигонов», которые были наложены на основные жилые кварталы исследуемых городов. Слой «промышленная застройка» (рис. 1) создан по аналогии с жилой застройкой при помощи полигонов, которые наложены на контуры промышленных предприятий города - основных источников загрязнения окружающей среды.
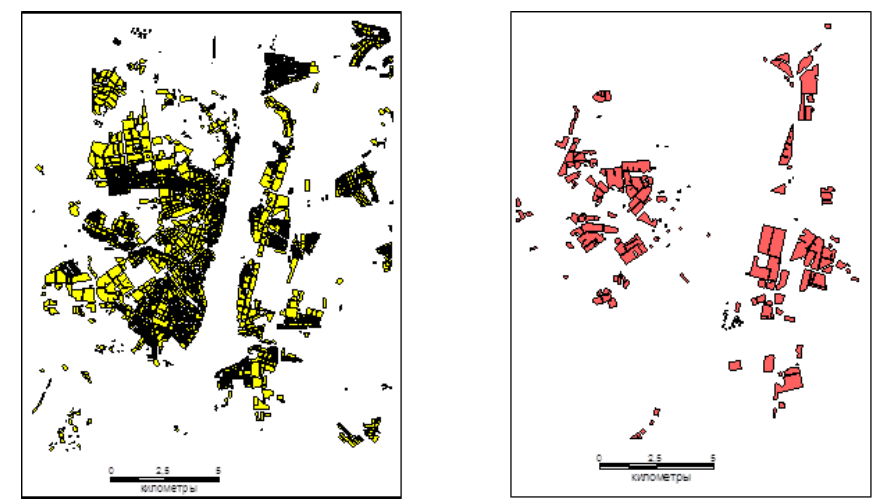

Рисунок 1 - Векторные слои «Жилая застройка» и «Промышленная застройка»

В таблицу данного слоя внесены названия предприятий, их почтовый адрес, удельный вклад выбросов загрязняющих веществ в атмосферу от общегородского и класс вредности предприятия. На основании данного слоя предоставляется возможным оценить районы предполагаемого локального воздействия промышленных зон с учетом розы ветров, а также размещение фрагментов жилой застройки в пределах санитарно-защитных зон промышленных предприятий, что наблюдается в ряде городов. Например, в Воронеже (около 8 тысяч человек проживают в санитарно-защитных зонах предприятий 1 и 2 классов вредности).

Слой «зелёные насаждения» (рис. 2) создан при помощи полигонов. Данный слой позволяет оценить возможное «задерживание» распространения токсических веществ от промышленных предприятий и автомобильных дорог. Слой «улицы» создан при помощи линий и полилиний. При помощи данного слоя предоставляется возможным ориентироваться в расположении основных улиц города. 

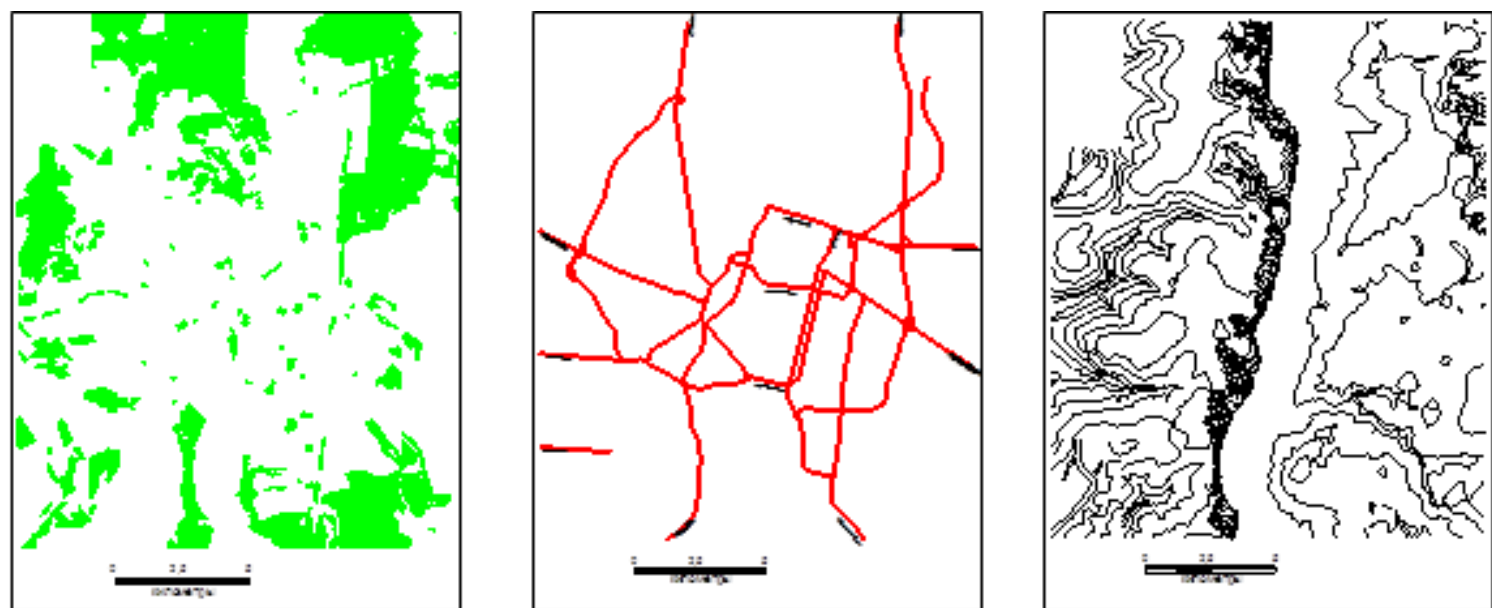

Рисунок 2 - Векторные слои «зелёные насаждения», «крупные автодороги» и «рельеф»

Слои «крупные автодороги» (рис. 2) и «железные дороги» созданы посредствам линий и полилиний. Слой «крупные автодороги» отображает основные транспортные артерии исследуемых территорий. Поскольку автотранспорт является основным источником свинца, формальдегида, нефтепродуктов и других загрязнителей, сопоставляя данный слой со слоем «жилая застройка», можно оценить зоны возможного превышения ПДК данных загрязнителей в окружающей среде. Железнодорожный транспорт менее токсичен с экологической точки зрения, однако, сопоставляя слой «железные дороги» с «жилой застройкой», можно выявить жилые кварталы, в которых наблюдается шумовой дискомфорт и локальное химическое загрязнение среды. Слой «рельеф» (рис. 2) создан при помощи сглаженных полилиний. Данный слой позволяет оценить распространение загрязнителей окружающей среды с учётом относительной высоты той или иной территории. Так, например, во впадинах концентрация загрязнителей окружающей среды обычно выше, чем на возвышенностях. Также данный слой позволяет прогнозировать аэрацию того или иного участка городской территории. Слои «сады» и «кладбища» созданы при помощи полигонов. Слой «сады» отображает основные посадки плодовых деревьев на территории города, а слой «кладбища» отображает расположение основных кладбищ города.

Слой «объекты гидрологии» включает в себя все водоёмы, расположенные на городов - реки, озёра, пруды и прочие водоёмы. Слой «границы районов», созданный при помощи линий и полилиний, показывает расположение границ муниципальных районов, разделяющих города.

Созданная по данному принцыпу картооснова урбанизированной территории (рисунок 3). служит основой для пространственного отображения и анализа эколого-геохимических и медико-статистических данных.

Для пространственной оценки формирования зон геохимического загрязнения окружающей среды созданы слои с точечными объектами, в таблицах атрибутов которых приведены данные геоэкологических исследований - «атмосфера», отображающий месторасположение точек отбора проб воздуха и «почва», отображающий месторасположение точек отбора проб почвы.

Создание геоинформационных ресурсов для пространственного анализа геоэкологических данных урбанизированной территории Адлерского района г. Сочи выполнялось по блочному (модульному) принципу, что даёт возможность расширять систему за счет добавления новых блоков (программ) или работать только с определенной частью (модулем) ГИС. Созданные геоинформационные ресурсы могут использоваться как справочная система о геохимическом состоянии окружающей среды в различных частях урбанизированной территории, а также как инструмент математического анализа данных, имитационного моделирования и прогнозирования возникновения зон экологических рисков под воздействием экологогеохимических факторов окружающей среды. 


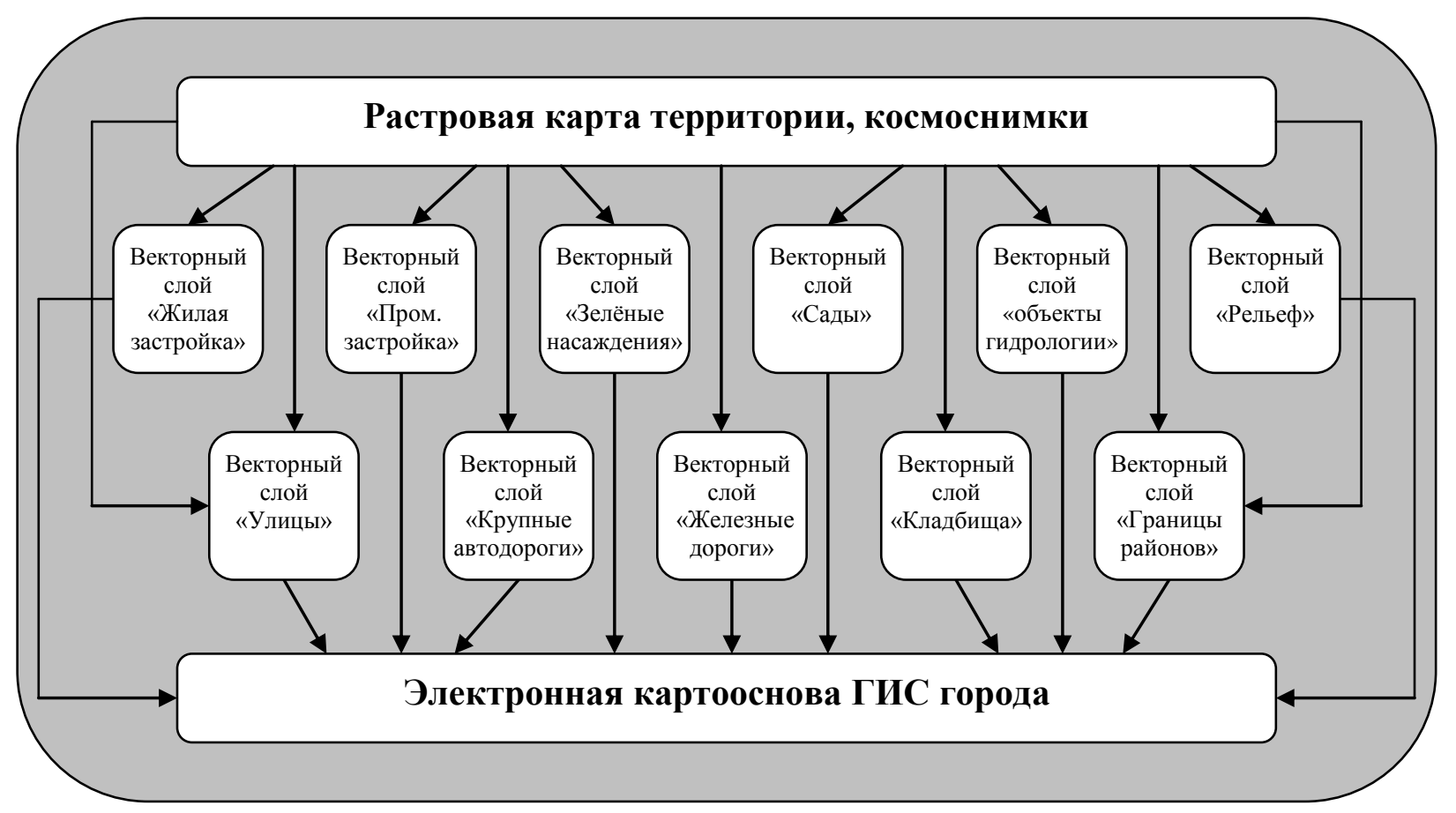

Рисунок 3 - Структура электронной картоосновы ГИС урбанизированной территории блоки:

В структуру геоинформационных ресурсов входят следующие стандартные для ГИС данного типа

Программно-техническое обеспечение. Включает устройства ввода-вывода графической информации: сканеры и векторизаторы (картографические редакторы, такие как ArcGIS, MapInfo, ГИС «Kapта», Surfer и др.). Для построения и вывода картографических изображений используются цветные лазерные и струйные печатающие устройства - сканеры и плоттеры. Для обеспечения диалогового режима пользователя в состав графической системы включается также цветной графический дисплей.

База данных. В качестве СУБД (средства управления базами данных) была использована программная оболочка ArcGIS, а также для проведения математико-статистических операций в качестве вспомогательнай программной среды использован программный пакет Ms Excel с надстройками. В БД хранятся данные о геохимическом загрязнении урбанизированной территории, а также коэффициенты уравнений модели, используемых в режиме имитационного моделирования. Для поиска и выборки данных используются различные команды запросов пользователя. Использование или комбинирование различных команд дает возможность представлять результаты запроса в различном виде: табличном, графическом, картографическом.

Система геоинформационного моделирования. В данную систему входит программное обеспечение, предназначенное для различных операций по математическому анализу данных - базовый модуль ArcGIS Arc Toolbox, a также надстройка 3D Analyst, базовый модуль MapInfo и др. Данные программы предоставляют возможность пространственно-статистической обработки информации, с прогнозом динамики показателя, математическое моделирование геоэкологической ситуации в городе.

Главный компонент созданных геоинформационных ресурсов - автоматизированное картографирование. Также в состав данной системы входит экспертное моделирование и экспертные оценки.

Диалоговая система. Данный функциональный блок представляет возможным функционирование ГИС как целостной системы, что обеспечивается системой управления диалогом пользователя. Также здесь осуществляется взаимосвязь между отдельными подсистемами ГИС, организуя диалоговое взаимодействие пользователя с системой.

Аналитическая система. Производит оценку и анализирует результаты работы ГИС. Как и диалоговая система, данный блок рассчитан на различные режимы работы ГИС. Выбор сценариев напрямую связан с оценкой геоэкологических ситуаций и во многом опирается на знание эксперта о наиболее типичных или вероятных условиях поведения изучаемого природного объекта под воздействием возмущающих факторов.

Картографическая информация в ГИС хранится в 2 группах данных: метрической и тематической. Метрические данные характеризуют пространственно-географические объекты урбанизированной территории - селитебную и общественно-деловую эколого-функциональные зоны, зелёные насаждения, гидрологическую сеть и другие объекты, описанные выше, а тематические - смысловое содержание карты, например, загрязнение почвы нефтепродуктами, количественные показатели экологического риска и т.д. 
В ГИС-пакетах ArcGIS и MapInfo каждый слой состоит из картографического изображения и соответствующего ему списка созданных объектов заданной пользователем структуры. Таким образом, устанавливается виртуальная связь между базой данных и картой, что необходимо для визуализации результатов анализа данных, тематического картографирования, причем любое изменение информации в списке автоматически отражается на тематической карте, что особенно важно для оперативного геоэкологического мониторинга.

Универсальность и многофункциональность разработанных геоинформационных ресурсов предоставляет возможность обмениваться данными с другими информационными ресурсами, хранящимися в таких распространенных СУБД, как Lotus, dBASE, STATISTIKA и др.

На основе разработанных геоинформационных ресурсов, представляется возможным проведение комплексного исследования факторов экологической безопасности урбанизированных территорий загрязнения атмосферы и почвенного покрова, а также оценки экологического риска для населения.

На территории России расчёт уровней риска в большинстве случаев производится в соответствии с руководством Р 2.1.10.1920-04 (Руководство по оценке риска для здоровья населения при воздействии химических веществ, загрязняющих окружающую среду) [Куролап и др., 2008]. Например, проведя расчёт суммарного неканцерогенного риска возникновения хронических заболеваний (НI) было установлено расположение зон высокого экологического риска в Железнодорожном районе города, микрорайоне «Машмет» Левобережного района, Советском районе и в районе ул. Транспортная Центрального района (рис. 4,5).

Таким образом, представляется возможным выделить следующий алгоритм геоинформационного обеспечения исследований параметров экологической безопасности:

1. Формирование и ведение базы данных ГИС - периодическое проведение экологогеохимических исследований.

2. Обработка баз данных - статистическая обработка данных, проведение текущих расчётов.

3. Создание картоосновы ГИС - создание «слоёв» векторной карты.

4. Геокодирование данных - трансформация данных эколого-геохимических исследований в систему координат векторной картоосновы.

5. $\quad$ ГИС-картографирование - построение тематических карт.

6. $\quad$ Анализ данных, проектирование - разработка приоритетных мероприятий по оптимизации городской среды.

Исследования выполнены при поддержке гранта президента Российской Федераџии для государственной поддержки молодых российских учёных - кандидатов наук (проект МК-1682.2014.5)

Библиографический список:

1. Епринцев С.А., Куролап С.А., Дубровин О.И., Дубровина И.В., Минников И.В. Экологическая безопасность урбанизированных территорий (на примере населённых пунктов Воронежской области) // Вестник Тамбовского университета. Серия: естественные и технические науки, г. Тамбов, Т.18, № 5-3. - С. 2902-2904.

2. Куролап С.А., Епринцев С.А., Клепиков О.В. и др. Воронеж: среда обитания и зоны экологического риска. - Воронеж: Издательство «Истоки», 2010. - 207 стр.

3. Куролап С. А., Мамчик Н.П., Клепиков О.В. Оценка риска для здоровья населения при техногенном загрязнении городской среды. - Воронеж : ВГУ, 2006. - 220 с.

4. http://www.loi.sscc.ru/gis/geoeco/use_gis_eco.htm 


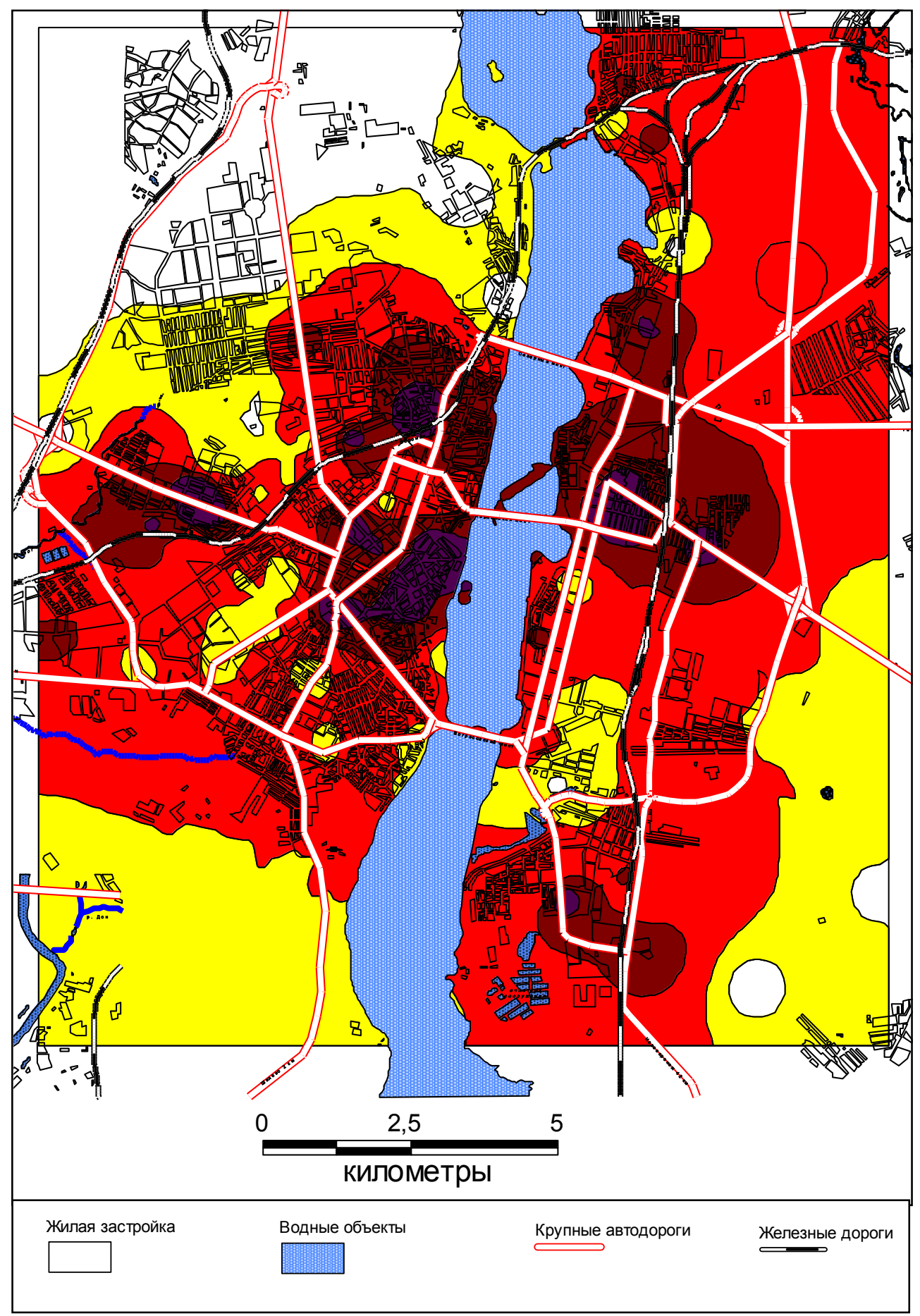

Суммарный уровень неканцерогенного риска возникновения хронических заболеваний

\begin{tabular}{|c|}
\hline НI менее 4 \\
\hline НІ от 4 до 7 \\
\hline НІ от 7 до 10 \\
\hline Н от 10 до 13 \\
\hline Нl более 13 \\
\hline
\end{tabular}

Рисунок 4 - Суммарный неканцерогенный риск в тёплый период года 


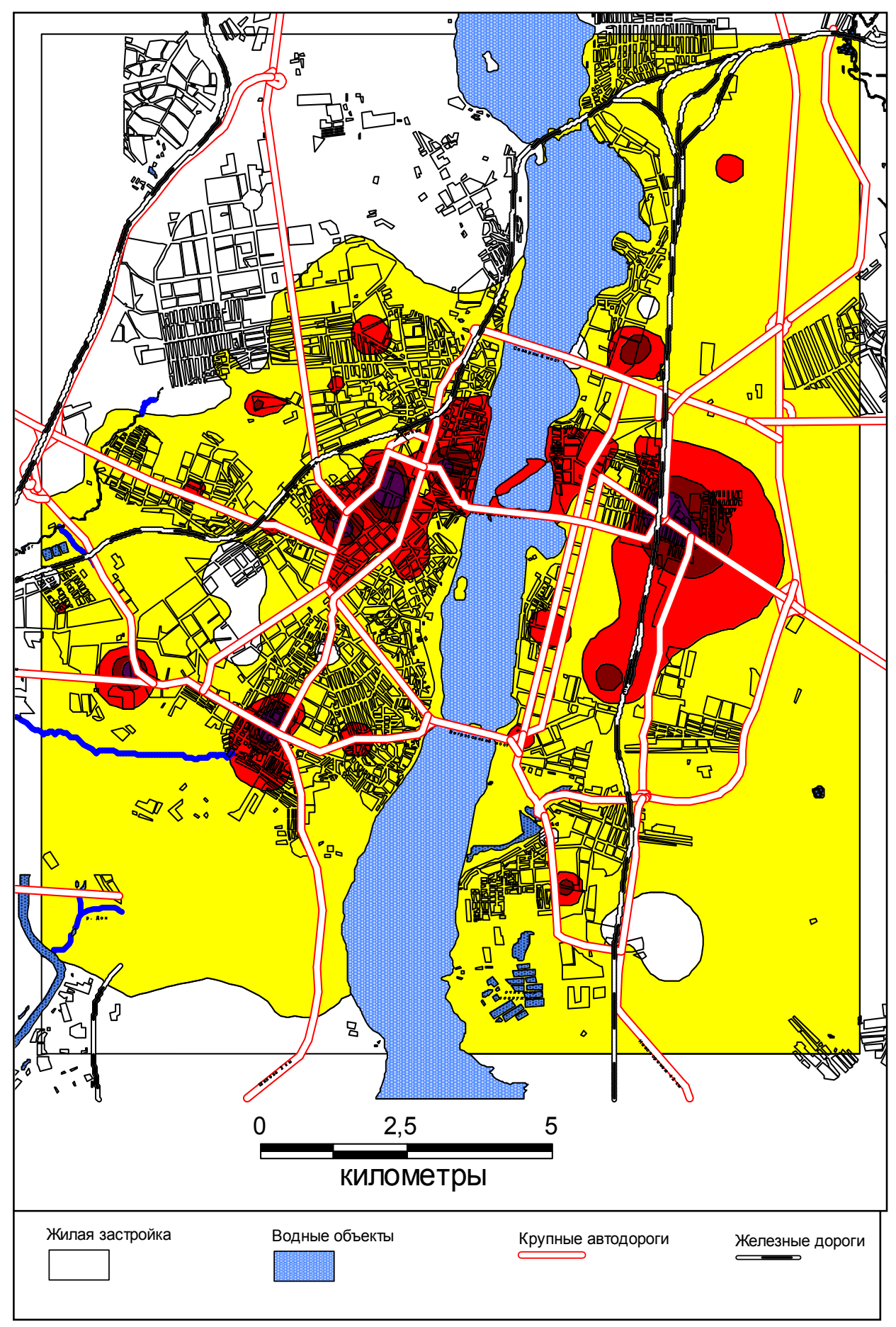

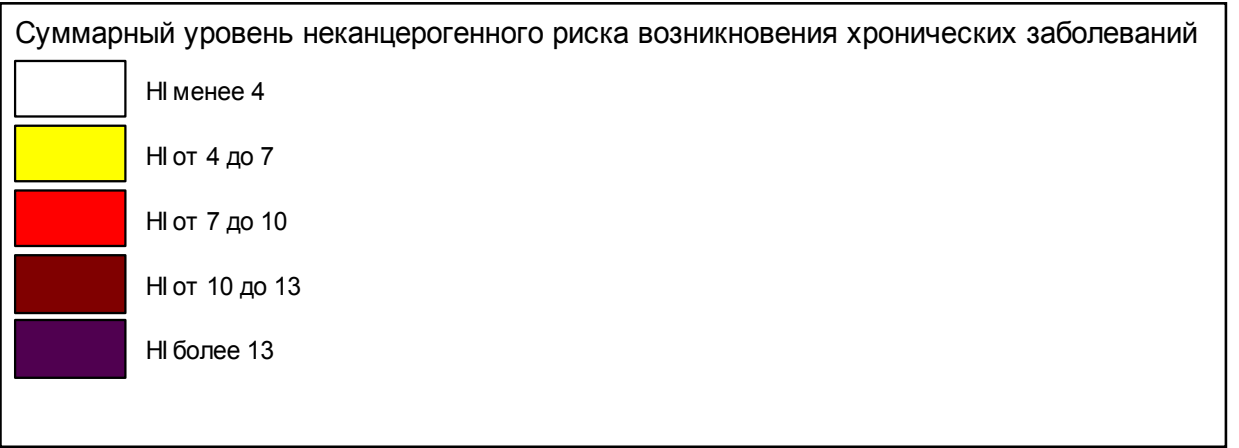

Рисунок 5 - Суммарный неканцерогенный риск в холодный период года 